\title{
Delayed Postpolypectomy Bleeding
}

\author{
Hyun Shig Kim \\ Department of Surgery, Seoul Song Do Colorectal Hospital, Seoul, Korea
}

See Article on Page 13-16

Is delayed bleeding after a colonoscopic polypectomy inevitable? Frankly speaking, I would answer 'Yes'. I hate to say this, but I have to admit that delayed bleeding after a polypectomy is the stern reality that has been encountered by the endoscopists ever since they first started to perform endoscopic polypectomies. When delayed bleeding occurs, it embarrasses both the endoscopist and the patient and even frustrates them .

The bleeding incidence rate varies in different reports and can be up to $10.2 \%$ [1]. Kim and his colleagues [2] reported a $0.17 \%$ bleeding rate in 2000 . The author's results show $0.95 \%$, which does not seem like a high incidence rate and may be acceptable in practice. It cannot be zero at the moment, but it can be reduced considerably by technical improvement. Most of the bleeding occurs within 1 week after the polypectomy. This report shows the same results regarding the timing of delayed bleeding. This suggests the existence of a critical time after a polypectomy, which is one to five days. This is different from posthemorrhoidectomy bleeding, which usually occurs one week after the hemorrhoidectomy [3].

Many studies have been performed to prevent delayed or secondary bleeding after an endoscopic polypectomy. There has been much improvement in polypectomy techniques and in the development of polypectomy devices and tools, and the complication rate has decreased accordingly. However, the goal to do away with the bleeding completely has yet to be reached. Mechanical devices such as hemoclips and detachable snares have been developed and are very useful these days. Those are very helpful in preventing delayed hemorrhage, but even they cannot guarantee the prevention of bleeding. Nonetheless, endoscopists have to keep some

Correspondence to: Hyun Shig Kim, M.D.

Department of Surgery, Seoul Song Do Colorectal Hospital, 366-144

Sindang 3-dong, Jung-gu, Seoul 100-453, Korea

Tel: +82-2-2250-7368 9, Fax: +82-2-2233-8528

E-mail:mdkhs@hotmail.com

(c) 2011 The Korean Society of Coloproctology

This is an open-access article distributed under the terms of the Creative Commons Attribution NonCommercial License (http://creativecommons.org/licenses/by-nc/3.0) which permits unrestricted noncommercial use, distribution, and reproduction in any medium, provided the original work is properly cited. points in mind to reduce the complication rate. Excessive coagulation should be avoided. It could cause larger ulceration and consecutive hemorrhage. Proper use of hemoclips and detachable snares is useful and helpful, even though their use is not a one hundred percent guarantee. It is very important to bear the basic principle of colonoscopy in mind: "Don't bite off more than you can chew". It is also important to prepare proper facilities and to have proper personnel to manage the delayed bleeding when it occurs. Moreover, fundamental studies to eliminate postpolypectomy bleeding should be continued.

\section{REFERENCES}

1. Dobrowolski S, Dobosz M, Babicki A, Głowacki J, Nałecz A. Blood supply of colorectal polyps correlates with risk of bleeding after colonoscopic polypectomy. Gastrointest Endosc 2006;63:1004-9.

2. Kim HS, Kim KU, Park WK, Cho KA, Hwang DY, Kang YW, et al. Delayed bleeding in a colonoscopic polypectomy: an experience with 5,236 polypectomies. J Korean Soc Coloproctol 2000; 16:462-8.

3. Kim HS, Lim SW, Oh JH, Lee JK. Secondary bleeding after hemorrhoidectomy. J Korean Surg Soc 1993;44:279-84. 